\title{
Unexpected pathological findings after laparoscopic cholecystectomy - analysis of 1131 cases
}

\author{
Katarzyna Bartosiak, Maciej Liszka, Tomasz Drazba, Krzysztof Paśnik, Michal R. Janik \\ Department of General, Oncologic, Metabolic and Thoracic Surgery, Military Institute of Medicine, Warsaw, Poland \\ Videosurgery Miniinv 2018; 13 (1): 62-66 \\ DOI: https://doi.org/10.5114/wiitm.2017.69594
}

\begin{abstract}
Introduction: Gallbladder specimens are routinely sent for histopathological examination after cholecystectomy in order to rule out the presence of unexpected pathological findings.

Aim: To establish the overall incidence of unexpected pathological findings in patients who underwent laparoscopic cholecystectomy for symptomatic gallbladder disease and determine whether the macroscopic appearance of the gallbladder in ultrasound examination could be a valid method for identifying patients with gallbladder malignancy. Material and methods: A retrospective study was conducted between 2013 and 2015. All histological reports $(n=1131)$ after cholecystectomy were searched for unexpected pathological findings. In cases where unexpected pathological findings were identified the additional analysis of preoperative abdominal ultrasound examination (USG) was done to determine the usefulness of USG in diagnosis of gallbladder malignancy.

Results: Of the 1131 patients included in the study, 356 (31.47\%) were male and 774 (68.43\%) were female. Unexpected pathological findings were present in 21 cases. The overall incidence of unexpected pathological findings was $1.86 \%$. Only in 5 patients were suspicious appearances of gallbladder observed in preoperative ultrasound examination. In 16 patients there was no suspicion of malignancy. The positive predictive value of USG was 0.238.

Conclusions: The incidence of unexpected pathological findings after laparoscopic cholecystectomy was $1.86 \%$. Ultrasonography has low positive predictive value for identifying patients with malignant findings in a gallbladder specimen.
\end{abstract}

Key words: cholecystectomy, gallbladder, gallbladder malignancy, histopathological examination, ultrasound examination.

\section{Introduction}

Cholecystectomy is one of the most commonly performed surgical procedures. The laparoscopic approach is safe and feasible [1]. However, other minimal accesses have been described and may be more popular in the near future [2, 3]. The main indications are gallstone-related diseases and, therefore, changes related to gallstone pathology are commonly observed during routine histological examination (i.e. chronic or acute cholecystitis, empyema, mucocele, cholesterol deposits) [4]. Pathology guidelines still advise routine histological examination of gallbladder specimens due to the possibility of unexpected pathological findings, including gallbladder carcinoma (CaGB), biliary intraepithelial neoplasia (BilIN), epithelial dysplasia or metastasis from other organs [5]. This is supported by data showing that incidental findings in cases of CaGB during routine histopathology vary from $0.17 \%$ to $3.3 \%$, with a range of $0.4-0.7 \%$ in Western countries [6]. On the other hand, a selective approach for histological examina-

\section{Address for correspondence}

Michal R. Janik MD, Department of General, Oncologic, Metabolic and Thoracic Surgery, Military Institute of Medicine, 128 Szaserów St, 04-141 Warsaw, Poland, phone: +48 602780 960, e-mail: janiken@gmail.com 
tion of gallbladder specimens has been proposed by various authors, when considering the overall large scale economic implications and the low prevalence of the disease [7-9].

\section{Aim}

The aim of this study was to: (1) establish the overall incidence of unexpected pathological findings in patients who underwent laparoscopic cholecystectomy for symptomatic gallbladder disease and (2) determine whether the macroscopic appearance of the gallbladder in ultrasonography could be a valid method for identifying patients with gallbladder malignancy.

\section{Material and methods}

Between January 2013 and December 2015, a total of 1131 laparoscopic and open cholecystectomies were performed in a single institution. Clinical data were retrospectively collected and included age, sex, body mass index (BMI), indications for surgery, preoperative ultrasonography, methods of operation, intraoperative findings, histopathological reports and postoperative complications. Each cholecystectomy case was assessed for unexpected pathological findings detected in the histopathological examination. Unexpected pathological findings were defined as the presence of one of the following: adenocarcinoma, epithelial dysplasia, biliary intraepithelial neoplasia (BillN), primary and secondary (metastatic) tumors of the gallbladder. In cases where unexpected pathological findings were identified, an additional preoperative abdominal ultrasound examination (USG) was performed to determine the usefulness of USG in the diagnosis of gallbladder malignancy.

\section{Statistical analysis}

Data were analyzed using SAS University Edition software (SAS Institute Inc., Cary, NC, USA). Logistic regression was performed to identify risk factors for unexpected pathological findings. Demographic variables were included in the analysis (age, gender and $\mathrm{BMI})$.

\section{Results}

Of the 1131 patients included in the study, 356 (31.47\%) were male and 774 (68.43\%) were female. The youngest patient who underwent a cholecystec- tomy was 19 years old and the oldest was 92 years old. The mean age was $55 \pm 15$ years. Descriptive characteristics are shown in Table I. The majority of patients underwent laparoscopy ( $n=1064,94 \%)$, while open surgery was performed in 16 (1.4\%) cases. Forty-three (3.8\%) procedures were started in laparoscopy, but had to be converted to the open technique due to operative findings/complications. One thousand and four (75.4\%) operations were per-

Table I. Overview of 1131 patients in the study $(N=1131)$

\begin{tabular}{|c|c|}
\hline Parameter & Value \\
\hline \multicolumn{2}{|l|}{ Sex, $n(\%):$} \\
\hline Male & $356(32.27)$ \\
\hline Female & $774(68.43)$ \\
\hline \multicolumn{2}{|l|}{ Age [years]: } \\
\hline Mean & $55 \pm 15$ \\
\hline Range & 19-92 \\
\hline \multicolumn{2}{|c|}{ Method of operation, $n(\%)$ : } \\
\hline Laparoscopy & $1064(94)$ \\
\hline Laparotomy & $16(1.4)$ \\
\hline Conversion & $43(3.8)$ \\
\hline \multicolumn{2}{|c|}{ Histopathological findings, $n(\%)$ : } \\
\hline Chronic inflammation & $382(33.76)$ \\
\hline Cholelithiasis & $273(24.14)$ \\
\hline Purulent cholecystitis & $312(27.59)$ \\
\hline Polyps & $17(1.5)$ \\
\hline Pathological findings & $21(1.86)$ \\
\hline \multicolumn{2}{|l|}{ Body mass index [kg/m²]: } \\
\hline Range & $15.2-58.4$ \\
\hline Mean & $28.6 \pm 5.6$ \\
\hline \multicolumn{2}{|l|}{ Operation priority, $n$ (\%): } \\
\hline Emergency procedure & $92(6.91)$ \\
\hline Postponed procedure & $35(2.62)$ \\
\hline Planned procedure & $1004(75.4)$ \\
\hline \multicolumn{2}{|l|}{ Hospitalization [days]: } \\
\hline Mean & 3.74 \\
\hline Duration & $1-31$ \\
\hline
\end{tabular}


formed as planned. Emergency surgery was necessary in $92(6.91 \%)$ cases. Thirty-five $(2.62 \%)$ patients were treated with interval cholecystectomy between 4-8 weeks after the initial episode of acute cholecystitis. The mean length of hospitalization was 3.7 \pm 2.3 days. The mean BMI was $28.6 \pm 5.6 \mathrm{~kg} / \mathrm{m}^{2}$.

Unexpected pathological findings were present in 21 cases. The overall incidence of unexpected pathological findings was $1.86 \%$. All findings are listed in Table II. Out of 21 cases with unexpected pathological findings, the most common histopathological diagnoses were partially tubular, partially papillary adenocarcinoma $(n=7,0.61 \%)$, pseudopyloric metaplasia $(n=4,0.35 \%)$, and minor grade epithelial dysplasia $(n=3,0.27 \%)$. The majority of the rest of the 1131 gallbladder specimens' histological findings were chronic inflammation $(n=382$, $33.8 \%)$, purulent cholecystitis $(n=312,27.6 \%)$, cholelithiasis $(n=273,21.5 \%)$ and gallbladder polyps $(n=17,1.5 \%)$.

The patients with unexpected findings had a mean age of $65 \pm 13$ years. The mean BMI was 27.5 $\pm 5 \mathrm{~kg} / \mathrm{m}^{2}$. Fifteen $(71 \%)$ were female and $6(29 \%)$ were male. The majority of patients $(n=18,85 \%)$ underwent a laparoscopic operation, 1 (5\%) patient had open surgery and in $2(1 \%)$ cases there was conversion to the open technique. Nineteen (90\%) operations were performed as planned. Emergency surgery was necessary in $2(10 \%)$ cases. The mean length of hospitalization was $4.48 \pm 2.82$ days. Logistic regression analysis revealed a correlation be-

Table II. Analysis of unexpected histopathological findings $(N=1131)$

\begin{tabular}{|ll|}
\hline Pathological findings & $N(\%)$ \\
\hline $\begin{array}{l}\text { Partially tubular, partially papillary adeno- } \\
\text { carcinoma }\end{array}$ & $7(0.61)$ \\
\hline Biliary adenocarcinoma & $1(0.09)$ \\
\hline Well-differentiated adenocarcinoma & $1(0.09)$ \\
\hline $\begin{array}{l}\text { Adenocarcinoma with medium grade dyspla- } \\
\text { sia of glandular epithelium }\end{array}$ & $1(0.09)$ \\
\hline High grade intraepithelial neoplasia BILLIN-3 & $1(0.09)$ \\
\hline $\begin{array}{l}\text { Low grade biliary intraepithelial neoplasia } \\
\text { BILLIN-1 }\end{array}$ & $2(0.18)$ \\
\hline Pseudopyloric metaplasia & $4(0.35)$ \\
\hline Minor grade epithelial dysplasia & $3(0.27)$ \\
\hline Metastatic breast cancer & $1(0.09)$ \\
\hline
\end{tabular}

tween the presence of unexpected findings and age (OR $=1.047,95 \% \mathrm{Cl}: 1.010-1.085, p=0.0125)$. Body mass index and gender were not risk factors for unexpected findings in histological examination, and were: $\mathrm{OR}=0.957,95 \% \mathrm{Cl}: 0.861-1.064, p=0.417$ and $\mathrm{OR}=0.939,95 \% \mathrm{Cl}: 0.32-2.758, p=0.908$, respectively.

The ultrasonography results were analyzed in all 21 cases of unexpected pathological findings confirmed by histopathological examinations. Only 5 patients had a suspicious appearance of the gallbladder observed in preoperative ultrasonography. In the remaining 16 patients, there was no suspicion of

Table III. Analysis of 21 cases of malignancy confirmed by histopathological examination $(N=21)$

\begin{tabular}{|c|c|}
\hline Parameter & Value \\
\hline \multicolumn{2}{|l|}{ Sex, $n(\%):$} \\
\hline Male & $6(29)$ \\
\hline Female & $15(71)$ \\
\hline \multicolumn{2}{|l|}{ Age [years]: } \\
\hline Mean & $65 \pm 13$ \\
\hline Range & $34-83$ \\
\hline \multicolumn{2}{|c|}{ Method of operation, $n(\%)$ : } \\
\hline Laparoscopy & $18(85)$ \\
\hline Laparotomy & $1(5)$ \\
\hline Conversion & $2(10)$ \\
\hline \multicolumn{2}{|l|}{ Body mass index $\left[\mathrm{kg} / \mathrm{m}^{2}\right]$ : } \\
\hline Range & $19.5-39.0$ \\
\hline Mean & $27.43 \pm 5.01$ \\
\hline \multicolumn{2}{|c|}{ Pre-operative suspicion, $n$ (\%): } \\
\hline USG positive & $5(24)$ \\
\hline USG negative & $16(76)$ \\
\hline \multicolumn{2}{|l|}{ Operation priority, $n(\%)$ : } \\
\hline Emergency procedure & $2(10)$ \\
\hline Postponed procedure & 0 \\
\hline Planned procedure & $19(90)$ \\
\hline \multicolumn{2}{|l|}{ Hospitalization [days]: } \\
\hline Mean & $4.48 \pm 2.82$ \\
\hline Duration & $3-15$ \\
\hline
\end{tabular}


malignancy. The positive predictive value (PPV) of ultrasonography in detecting unexpected pathological findings is 0.238 (Table III).

\section{Discussion}

In our study, the incidence of unexpected pathological findings was $1.86 \%$. Comparable data have been published by other authors $[5,7,10]$. For example, Samad reported an incidence of $1.1 \%$ of malignancy in patients who underwent cholecystectomy for presumed chronic cholecystitis with cholelithiasis [11]. Gallbladder malignancy usually does not have any characteristic clinical features in over $90 \%$ of patients presenting symptoms of acute or chronic cholecystitis [5]. Most of the patients in our study presented with prior history of chronic cholecystitis, and there were no symptoms or signs suggesting an underlying malignancy in any of the patients. Many authors suggest that ultrasonography has low diagnostic accuracy for both advanced and early gallbladder cancer [5, 12]. Only 5 of the unexpected pathological findings in this study were suspected on preoperative ultrasound. In a similar study by Siddiqui et al., none of the six carcinomas were suspected on ultrasound [5]. This contrasts with a study by De Zoysa et al. [13] in which all four cancers were suspected either on preoperative ultrasonography or during surgery. The authors suggest a more selective approach to gallbladder histology. Similar observations and recommendations were also made in a study by Darmas et al. [7]. Recently, reports have also questioned the role of routine histopathological examination in all cholecystectomy specimens [8]. They state that the incidence of incidental gallbladder carcinoma is too low to justify routine histopathological examination and that the routine histopathological examination of all cholecystectomy specimens overburdens pathology departments and hospital resources. A selective approach for histological examination of gallbladders was suggested $[5,7-9,14]$. The proposed selective criteria were based on the intraoperative macroscopic appearance of the gallbladder. However, there are still reports in which unexpected findings were diagnosed only with the final histological examination. Byars et al. [15] suggested that advanced age and female sex combined with the data from radiological investigations, intra-operative macroscopic findings and the clinical picture of the patient could further increase the accuracy of the selective criteria. Our analysis confirmed the association between age and the risk of unexpected findings. However, the association was not present regarding gender and BMI.

Moreover, there is a discussion regarding the cost of histopathological examination. Mohamed and colleagues postulate the importance of estimating the economic implications of a routine histological approach and the advantages of a selective approach [16]. Byars et al. also suggest that there is a feasible and effective approach to reducing the number of gallbladders sent for histology, which increases cost-effectiveness and saves time [15].

Therefore, we recommend routine histopathological examination of all gallbladders removed at surgery, as the preoperative USG examination has low positive predictive value. Despite the low incidence of unexpected pathological findings, some of them require further treatment and a selective approach may overlook serious disease.

There are some limitations to our study. Firstly, our study is retrospective. Prospective studies are necessary to further assess and test our findings. Secondly, the number of included patients is limited. In view of the low incidence of unexpected findings, a high number of patients is required to provide sufficient power. In order to safely modify the current guidelines, a prospective, multicenter study must be performed.

\section{Conclusions}

The incidence of gallbladder carcinoma and other pathological findings in patients who underwent laparoscopic cholecystectomy for symptomatic gallbladder disease was $1.86 \%$. Advanced age was associated with higher risk of unexpected findings. Ultrasonography has low positive predictive value in detecting unexpected pathological findings. Therefore, we strongly advocate conducting routine histopathology of all cholecystectomy specimens.

\section{Conflict of interest}

The authors declare no conflict of interest.

\section{References}

1. Śmigielski JA, Piskorz $九$, Koptas W. Comparison of treatment costs of laparoscopic and open surgery. Videosurgery Miniinv 2015; 10: 437-41. 
2. Donmez T, Uzman S, Ferahman S, et al. New advantageous tool in single incision laparoscopic cholecystectomy: the needle grasper. Videosurgery Miniinv 2016; 11: 38-43.

3. Wroblewski T, Kobryn K, Nazarewski Ł, et al. Minilaparoscopic cholecystectomy - the new non-visible scars technique. Preliminary report of first series. Videosurgery Miniinv 2015; 10: 150-4.

4. Slater M, Booth MI, Dehn TCB. Cost-effective laparoscopic cholecystectomy. Ann R Coll Surg Engl 2009; 91: 670-2.

5. Siddiqui FG, Memon AA, Abro AH, et al. Routine histopathology of gallbladder after elective cholecystectomy for gallstones: waste of resources or a justified act? BMC Surg 2013; 13: 26.

6. Van Vliet JLP, Van Gulik TM, Verbeek PCM. Is it necessary to send gallbladder specimens for routine histopathological examination after cholecystectomy? The use of macroscopic examination. Dig Surg 2014; 30: 472-5.

7. Darmas B, Mahmud S, Abbas A, et al. Is there any justification for the routine histological examination of straightforward cholecystectomy specimens? Ann R Coll Surg Engl 2007; 89: 238-41.

8. Romero-Gonzalez RJ, Garza-Flores A, Martinez-PerezMaldonado L, et al. Gallbladder selection for histopathological analysis based on a simple method: a prospective comparative study. Ann R Coll Surg Engl 2012; 94: 159-64.

9. Chin KF, Mohammad AA, Khoo YY, et al. The impact of routine histopathological examination on cholecystectomy specimens from an Asian demographic. Ann R Coll Surg Engl 2012; 94: 165-9.

10. Lohsiriwat $V$, Vongjirad A, Lohsiriwat D. Value of routine histopathologic examination of three common surgical specimens: appendix, gallbladder, and hemorrhoid. World I Surg 2009; 33: 2189-93.

11. Samad A. Gall bladder carcinoma in patients undergoing cholecystectomy for cholelithiasis. J Pak Med Assoc 2005; 55: 497-9.

12. Delis S, Bakoyiannis A, Madariaga J, et al. Laparoscopic cholecystectomy in cirrhotic patients: the value of MELD score and ChildPugh classification in predicting outcome. Surg Endosc Other Interv Tech 2010; 24: 407-12.

13. De Zoysa MIM, De Silva SKLA, Illeperuma A. Is routine histolog ical examination of gall bladder specimens justifiable? Ceylon Med J 2010; 55: 13-6.

14. Mittal R, Jesudason MR, Nayak S. Selective histopathology in cholecystectomy for gallstone disease. Indian I Gastroenterol 2010; 29: 32-6.

15. Byars JPD, Pursnani K. An alternative approach to sending all gallbladders for histology following cholecystectomy? Surg Sci 2012; 3: 15-20.

16. Elshaer M, Gravante G, Yang Y, et al. Routine versus selective histologic analysis of gallbladder specimens for the detection of incidental gallbladder cancers. A retrospective review over 9 years of activity with a special focus on patients' age. Am J Surg 2014; 208: 444-9.

Received: 21.04.2017, accepted: 3.07.2017. 